\title{
Comparison of Food and Aeroallergen Sensitivity between Adults and Children with Eosinophilic Esophagitis
}

\section{Prematta T, Kunselman A and Ghaffari G*}

Section of Allergy, Asthma and Immunology, Pennsylvania State College of Medicine, Hershey Medical Center, Pennsylvania, USA

\begin{abstract}
Rationale: Eosinophilic esophagitis (EoE) is an increasingly diagnosed disorder and evidence suggests that food and/or aeroallergen sensitivities play a role in the pathogenesis. The purpose of this study was to compare the likelihood of food and aeroallergen sensitivity in children versus adults with EoE.

Methods: After institutional review board approval, a retrospective chart review was conducted evaluating the work up performed on patients with EoE referred to allergists. A comparison was made between sensitivity to foods and aeroallergens based on age (children $\leq 18$ years compared to adults $\geq 19$ years).

Results: Medical records of 44 patients with biopsy proven diagnosis of EoE were reviewed retrospectively (19 children and 25 adults). Compared with adults, children had significantly more evidence of IgE mediated sensitivity to egg (59\% versus $9 \%$; OR $13.2 ; 95 \% \mathrm{Cl}$ : $2.1-152.3 ; \mathrm{P}=0.002)$, milk $(61 \%$ versus $9 \%$; OR $14.4 ; 95 \% \mathrm{Cl}: 2.4-$ 165.8; $\mathrm{P}$ value $=0.001)$, and soy $(61 \%$ versus $14 \%$; OR 9.3; $95 \% \mathrm{Cl}: 1.8-67.7 ; \mathrm{P}=0.005)$. Children tended to have higher rates of positive patch testing to foods, but these differences did not reach statistical significance. IgE mediated aeroallergen sensitivities were not statistically different between children and adults when evaluating for trees, grasses, weeds, dust mites, animal danders and molds.

Conclusion: Our study suggests that among patients with EoE, children are more likely to have IgE mediated food sensitivities to egg, milk, and soy, when compared with adults. However, the occurrence of aeroallergen sensitivity in children and adults with EoE is similar. In the future, large prospective studies will help better delineate the association of EoE with food and aeroallergen sensitivity. This will potentially lead to appropriate interventions in different age groups.
\end{abstract}

Keywords: Eosinophilic esophagitis; Children; Adults; Food; Aeroallergen

\section{Introduction}

Eosinophilic esophagitis (EoE) is an increasingly diagnosed clinicopathological disorder affecting children and adults [1-3]. The clinical symptoms in children include vomiting, failure to thrive, heartburn, dysphagia, food refusal and abdominal pain [4-7]. In adults, intermittent dysphagia, with or without overt food impaction, is the most commonly reported symptom [4-8]. When clinical symptoms and endoscopic features suggest the diagnosis of EoE and after excluding infectious causes and autoimmune disorders, finding of at least 15 eosinophils per high power field makes the diagnosis of EoE [1,5-9].

There is a growing body of literature which suggests that food sensitivity identified by a combination of skin prick tests and atopy patch testing, play an important role in the pathogenesis of EoE [9-13]. Multiple studies of elemental or specific elimination diets in children with EoE have shown improvement of symptoms and decreased number of eosinophils in the esophagus [11-18]. Data supporting elemental or specific elimination diets in adults is not as compelling as it is in children [19]. Whether this is due to issues with compliance or differences in food sensitivity is not entirely clear. Recent studies suggest that aeroallergen sensitivity may play a role in the pathogenesis of EoE [20-22]. Whether aeroallergen sensitivity plays a causative role in all patients with EoE and how this will affect clinical management is unclear.

We sought to compare rates of food and aeroallergen sensitivity in children versus adults with EoE.

\section{Materials and Methods}

\section{Patient evaluation}

Skin Prick Test (SPT) with commercial allergen extracts (Greer
Laboratories Inc, Lenoir, NC) was performed with a panel of food extracts including: almond, apple, banana, brazil nut, cantaloupe, carrot, casein, celery, cherry, chicken, clam, codfish, corn, crab, egg, fish mix, hazel nut, lobster, milk, oat, peach, peanut, pecan, green beans, pistachio, white potato, rice, salmon, sesame seed, shellfish mix, shrimp, soy bean, strawberry, tomato, tuna, walnut, wheat, and whole bean cacao. They were also tested for perennial and seasonal aeroallergens prevalent in the area. Histamine and normal saline were used as positive and negative controls, respectively. A wheal of $3 \mathrm{~mm}$ greater than the negative control was considered a positive test. Serum in-vitro assays of specific IgE (ImmunoCap Phadia AB, Portage, Michigan) were performed in seven patients.

Patch testing for food was done using dry and commercially prepared foods. Testing with dry powdered foods was done for egg, milk, rice, barley, wheat, oat, potato, soy, peanut, and corn. Testing with commercially available single ingredient foods was done for apple, banana, peaches, carrots, green beans, sweet peas, beef, chicken, turkey, and ham. Commercially prepared baby foods were placed on

*Corresponding author: Gisoo Ghaffari, Section of Allergy, Asthma and Immunology, Pennsylvania State College of Medicine, Hershey Medical Center, Pennsylvania, USA, Tel: 717-531-6525 05; E-mail: gghaffari@hmc.psu.edu

Received July 16, 2011; Accepted September 10, 2011; Published September 20, 2011

Citation: Prematta T, Kunselman A, Ghaffari G (2011) Comparison of Food and Aeroallergen Sensitivity between Adults and Children with Eosinophilic Esophagitis. J Aller Ther S3:001. doi:10.4172/2155-6121.S3-001

Copyright: (c) 2011 Prematta T, et al. This is an open-access article distributed under the terms of the Creative Commons Attribution License, which permits unrestricted use, distribution, and reproduction in any medium, provided the original author and source are credited. 
Citation: Prematta T, Kunselman A, Ghaffari G (2011) Comparison of Food and Aeroallergen Sensitivity between Adults and Children with Eosinophilic Esophagitis. J Aller Ther S3:001. doi:10.4172/2155-6121.S3-001

Page 2 of 4

aluminum disks (Finn chambers on Scanpore, Allerderm Laboratories, Inc, Petaluma, CA). Dry foods were mixed with saline solution to obtain a paste-like consistency, and were then placed on the aluminum disks. Aluminum disks were placed on the patients back. Patches were removed at 48 hours, and were read at 72 hours [23]. The presence of erythema, papules, or vesicles on the skin was considered a positive test.

\section{Chart review}

After Institutional Review Board (IRB) approval was obtained, a retrospective chart review was conducted evaluating the work up performed on all patients with EoE referred to allergy/immunology at Penn State Hershey Medical Center. Medical records were reviewed from 7/1/2006-7/25/2009 to ensure history and esophageal biopsy results $(>15$ eosinophils per high-powered field, despite treatment with PPI) were consistent with a diagnosis of EoE. Food sensitivity was determined by IgE testing (skin prick test and/or serum specific IgE) and patch testing for foods. Aeroallergen sensitivity was determined by IgE testing (skin prick test and/or serum specific IgE). Results of food and aeroallergen sensitivity testing for children and adults with EoE were recorded and compared.

\section{Statistical analysis}

An exact logistic regression model was fit to compare the proportion of positive results for a given allergen between children (age $\leq 18$ years) and adults (age $>18$ years) [24]. All hypothesis tests were two-sided and the effect sizes from the exact logistic regression model comparing children to adults were quantified using odds ratios (OR) with exact 95\% confidence intervals (CI). As this was an exploratory analysis, no adjustments for multiple hypothesis testing were done. All analyses were performed using SAS software, version 9.1 (SAS Institute, Inc., Cary, NC). Statistical significance was defined as p-value less than 0.05 .

\begin{tabular}{|l|c|c|c|c|c|c|c|c|c|c|c|}
\hline \multicolumn{10}{|c|}{ Patient Demographics } \\
\hline Group & $\begin{array}{c}\text { Mean } \\
\text { Age } \\
\text { (Range } \\
\text { in Years) }\end{array}$ & Male & $\begin{array}{c}\text { Fe- } \\
\text { male }\end{array}$ & AR & $\begin{array}{c}\text { Asth- } \\
\text { ma }\end{array}$ & AD & FA & AR & $\begin{array}{c}\text { Asth- } \\
\text { ma }\end{array}$ & AD & FA \\
\hline Children & $\begin{array}{c}8.3 \\
\text { (range } \\
2-18)\end{array}$ & $63 \%$ & $37 \%$ & $68 \%$ & $47 \%$ & $26 \%$ & $26 \%$ & $47 \%$ & $67 \%$ & $29 \%$ & $18 \%$ \\
\hline Adults & $\begin{array}{c}38.1 \\
\text { (range } \\
21-68)\end{array}$ & $68 \%$ & $32 \%$ & $68 \%$ & $24 \%$ & $8 \%$ & $16 \%$ & $44 \%$ & $40 \%$ & $4 \%$ & $16 \%$ \\
\hline
\end{tabular}

Table 1:

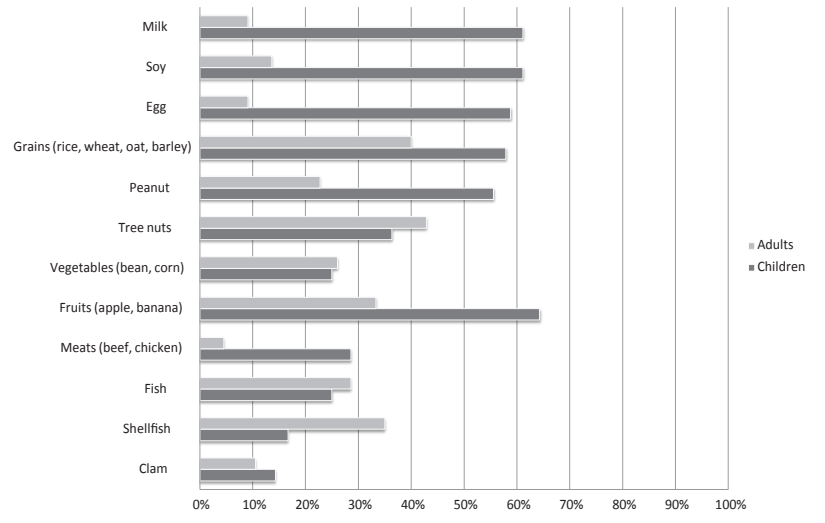

Figure 1: Comparison of IgE mediated food allergy in children vs. adults with EoE.

\section{Results}

\section{Demographics}

A total of 44 patient charts were reviewed, of those, 19 were children and 25 were adults. Age ranged from 2-68 years and there was a predominance of males in the study (Table 1).

\section{IgE mediated food sensitivity}

A total of $18 / 19$ children had evidence of at least one IgE mediated food allergy (95\%) and 21/25 (84\%) of adults had evidence of at least one IgE mediated food allergy. Compared to adults, children were statistically more likely to have evidence of $\operatorname{IgE}$ mediated allergy to egg (59\% versus 9\%; OR 13.2; 95\% CI: 2.1-152.3; $\mathrm{P}=0.002)$, milk (61\% versus $9 \%$; OR 14.4; 95\% CI: $2.4-165.8 ; \mathrm{P}=0.001)$, and soy $(61 \%$ versus $14 \%$; OR 9.3; 95\% CI: $1.8-67.7 ; \mathrm{P}=0.005)$. Furthermore, there was marginal evidence of children having higher IgE mediated peanut sensitivity (56\% versus $23 \%$; OR $4.1 ; 95 \%$ CI: $0.9-21.0 ; \mathrm{P}=0.07$ ), although this did not reach statistical significance (Figure 1). Finally, as age increased, there was a trend towards decreased total number of $\operatorname{IgE}$ mediated food allergies (Figure 2).

\section{Delayed food sensitivity}

With regards to patch testing for foods, $13 / 19$ (68\%) children and

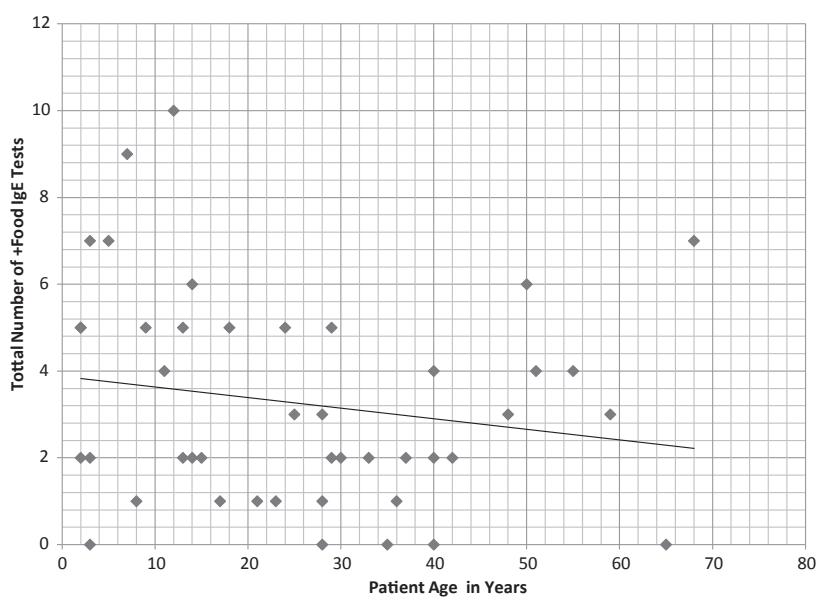

Figure 2: Total Number of Positive Food lgE Tests in Relation to Age

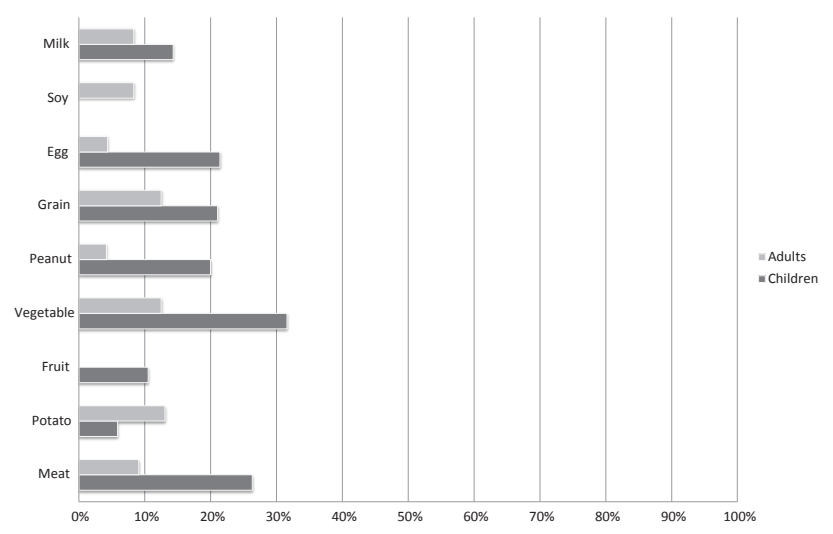

Figure 3: Comparison of Patch Testing for Foods in Children vs. Adults with EoE. 
10/24 (42\%) adults had at least one positive test. Although children tended to have higher rates of positive results to atopy patch tests with several foods, none of these reached statistical significance (Figure 3). Finally, as age increased, the total number of positive patch tests seemed to decrease (Figure 4).

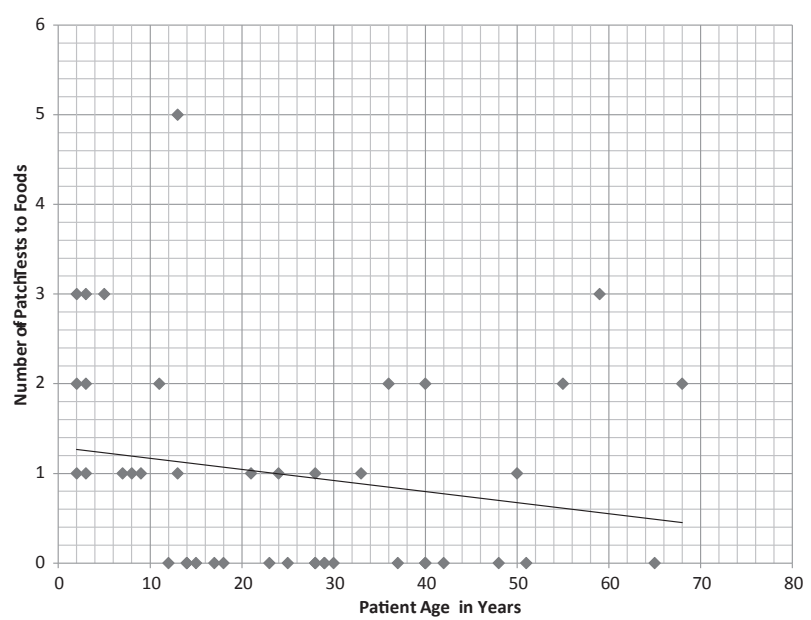

Figure 4: Total Number of Positive Patch Tests to Foods in Relation to Age

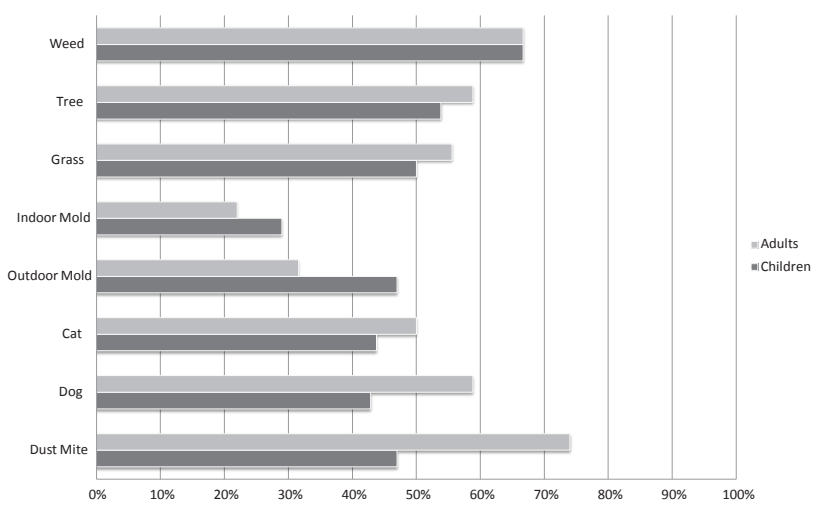

Figure 5: Comparison of lgE-mediated Aeroallergen Sensitivity in Children vs. Adults with EoE.

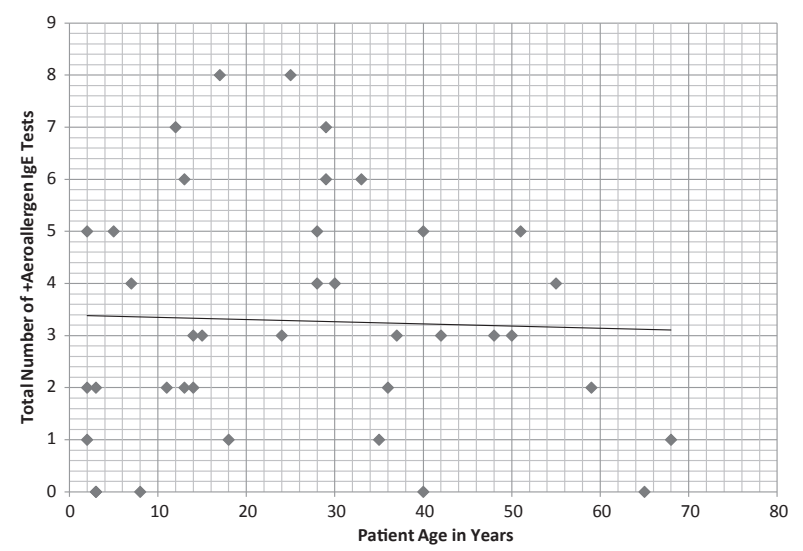

Figure 6: Total Number of Positive Aeroallergen IgE Tests in Relation to Age.

\section{IgE mediated aeroallergen sensitivity}

Evaluation for aeroallergen sensitivity via IgE testing was performed either through SPT or in-vitro IgE assays. Our data revealed 15/18 (83\%) children and 19/21 (90\%) adults had at least one positive test. There was no appreciable difference in aeroallergen sensitivity to trees, grasses, weeds, dust mite, animal dander, or molds in children compared to adults. As opposed to food sensitivity, there was not a trend towards lower numbers of positive tests with increasing age (Figures $5 \& 6$ ).

\section{Discussion}

Most of the available literature regarding food and aeroallergen sensitivities has been performed in pediatric age group [11-13,23]. This study includes adults, as well as children. In our study, children with EoE tended to have more evidence of IgE-mediated food sensitivity to milk, egg and soy compared to adults. Published data in children has revealed milk, egg and soy as the most commonly identified food allergens identified by SPT [11], however no similar study has been performed in adults. Our study is limited by the fact that this data was collected retrospectively and does not establish causality, which is inherent to retrospective studies. However, other studies in children support that SPT can appropriately identify foods that are playing a role in the pathogenesis of this disease [11-13].

The exact reason why adults have less evidence of IgE-mediated food sensitivity is not clear. It is possible that food sensitivities are not playing a major role in adult patients as opposed to children. This seems to be supported by a study performed by Simon et al, in which wheat and rye elimination diets in adults with EoE were not effective in controlling symptoms [19]. It is also possible that food allergies are only playing a role in a select population of adults for whom testing is positive; large prospective studies on specific elimination diets might yield positive results in these adults.

Additionally, our study did not show any differences in aeroallergen sensitivity between children and adults with EoE. Studies with larger groups of younger children, particularly under the age of 2 , may indeed find differences in aeroallergen sensitivity that ours did not detect. Current research implies aeroallergen sensitivity may be playing a causative role in this condition $[21,22]$. Therefore, it will be important to include both children and adults in future studies of the role of aeroallergen sensitivity in pathogenesis and treatment of EoE.

\section{Conclusion}

In patients with EoE, children are more likely to have evidence of food sensitivity than adults, but there was no difference in the rate of aeroallergen sensitivity between the two age groups. This implies that different factors may be playing a role in the pathogenesis of this disease in adults or that our current diagnostic tests are not adequate for identifying food sensitivities in this population. Large prospective studies will help better delineate the association of EoE with various allergens and appropriate interventions in different age groups of patients with EoE.

\section{References}

1. Liacouras CA, Furuta GT, Hirano I, Atkins D, Attwood SE, et al. (2011) Eosinophilic esophagitis: updated consensus recommendations for children and adults. J Allergy Clin Immunol 128: 3-20 e6; quiz 21-22.

2. Noel RJ, Putnam PE, Collins MH, Assa'ad AH, Guajardo JR, et al. (2004) Clinical and immunopathologic effects of swallowed fluticasone for eosinophilic esophagitis. Clin Gastroenterol Hepatol 2: 568-575.

3. Vanderheyden AD, Petras RE, DeYoung BR, Mitros FA (2007) Emerging 
Citation: Prematta T, Kunselman A, Ghaffari G (2011) Comparison of Food and Aeroallergen Sensitivity between Adults and Children with Eosinophilic Esophagitis. J Aller Ther S3:001. doi:10.4172/2155-6121.S3-001

eosinophilic (allergic) esophagitis: increased incidence or increased recognition? Arch Pathol Lab Med 131: 777-779.

4. Furuta GT, Liacouras CA, Collins MH, Gupta SK, Justinich C, et al. (2007) Eosinophilic esophagitis in children and adults: a systematic review and consensus recommendations for diagnosis and treatment. Gastroenterology 133: 1342-1363.

5. Orenstein SR, Shalaby TM, Di Lorenzo C, Putnam PE, Sigurdsson L, et al. (2000) The spectrum of pediatric eosinophilic esophagitis beyond infancy: a clinical series of 30 children. Am J Gastroenterol 95: 1422-1430.

6. Teitelbaum JE, Fox VL, Twarog FJ, Nurko S, Antonioli D, et al. (2002) Eosinophilic esophagitis in children: immunopathological analysis and response to fluticasone propionate. Gastroenterology 122: 1216-1225

7. Attwood SE, Smyrk TC, Demeester TR, Jones JB (1993) Esophageal eosinophilia with dysphagia. A distinct clinicopathologic syndrome. Dig Dis Sci 38: 109-116.

8. Potter JW, Saeian K, Staff D, Massey BT, Komorowski RA, et al. (2004) Eosinophilic esophagitis in adults: an emerging problem with unique esophageal features. Gastrointest Endosc 59: 355-361.

9. Assa'ad A (2009) Gastrointestinal eosinophil-mediated disorders and their treatment. Curr Allergy Asthma Rep 9: 26-29.

10. Bahna SL (2008) Reflections on current food allergy controversies: specific lgE test application, patch testing, eosinophilic esophagitis, and probiotics. Allergy Asthma Proc 29: 447-452.

11. Spergel JM, Andrews T, Brown-Whitehorn TF, Beausoleil JL, Liacouras CA (2005) Treatment of eosinophilic esophagitis with specific food elimination diet directed by a combination of skin prick and patch tests. Ann Allergy Asthma Immunol 95 336-343.

12. Spergel JM, Beausoleil JL, Mascarenhas M, Liacouras CA (2002) The use of skin prick tests and patch tests to identify causative foods in eosinophilic esophagitis. $J$ Allergy Clin Immunol 109: 363-368.

13. Spergel JM, Brown-Whitehorn T, Beausoleil JL, Shuker M, Liacouras CA (2007) Predictive values for skin prick test and atopy patch test for eosinophilic esophagitis. J Allergy Clin Immunol 119: 509-511.
14. Kelly KJ, Lazenby AJ, Rowe PC, Yardley JH, Perman JA, et al. (1995) Eosinophilic esophagitis attributed to gastroesophageal reflux: improvement with an amino acid-based formula. Gastroenterology 109: 1503-1512.

15. Kagalwalla AF, Sentongo TA, Ritz S, Hess T, Nelson SP, et al. (2006) Effect of sixfood elimination diet on clinical and histologic outcomes in eosinophilic esophagitis. Clin Gastroenterol Hepatol 4: 1097-1102.

16. Markowitz JE, Spergel JM, Ruchelli E, Liacouras CA (2003) Elemental diet is an effective treatment for eosinophilic esophagitis in children and adolescents. Am J Gastroenterol 98: 777-782.

17. Liacouras CA, Spergel JM, Ruchelli E, Verma R, Mascarenhas M, et al. (2005) Eosinophilic esophagitis: a 10-year experience in 381 children. Clin Gastroenterol Hepatol 3: 1198-1206.

18. Remedios M, Campbell C, Jones DM, Kerlin P (2006) Eosinophilic esophagitis in adults: clinical, endoscopic, histologic findings, and response to treatment with fluticasone propionate. Gastrointest Endosc 63: 3-12.

19. Simon D, Straumann A, Wenk A, Spichtin H, Simon HU, et al. (2006) Eosinophilic esophagitis in adults--no clinical relevance of wheat and rye sensitizations. Allergy 61: $1480-1483$.

20. Onbasi K, Sin AZ, Doganavsargil B, Onder GF, Bor S, et al. (2005) Eosinophil infiltration of the oesophageal mucosa in patients with pollen allergy during the season. Clin Exp Allergy 35: 1423-14231.

21. Fogg MI, Ruchelli E, Spergel JM (2003) Pollen and eosinophilic esophagitis. J Allergy Clin Immunol 112: 796-797.

22. Mishra A, Hogan SP, Brandt EB, Rothenberg ME (2001) An etiological role fo aeroallergens and eosinophils in experimental esophagitis. J Clin Invest 107: 8390.

23. Spergel JM, Brown-Whitehorn T (2005) The use of patch testing in the diagnosis of food allergy. Curr Allergy Asthma Rep 5: 86-90.

24. Hirji KF MC, Patel NR (1987) Computing distributions for exact logistic regression JASA 82: 1110-1117. 